\title{
MECHANISMS CONTROLLING THE IN-SITU FORMATION AND SUPERCONDUCTING PROPERTIES OF Bi-Sr-Ca-Cu-O FILMS:
}

R.T. Kampwirth, J.M. Grace, D.J. Miller, D.B. McDonald, K.E. Gray, M. Reiten,

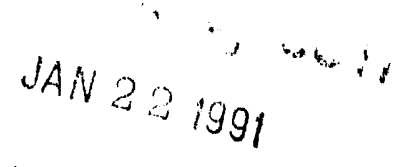

\author{
M. Ascolese, and H. Latvakoski \\ Materials Science Division \\ and \\ Science and Technology Center for Superconductivity
}

Argonne National Laboratory, Argonne, IL 60439 USA

To appear in Proceedings of 1990 Applied Superconductivity Conference, September 24-28, 1990, Snowmass, CO, to be published in IEEE Transactions on Magnetics, March 1991.

jmc

\section{DISCLAIMER}

\begin{abstract}
This report was prepared as an account of work sponsored by an agency of the United States Government. Neither the United States Government nor any agency thereof, nor any of their employees, makes any warranty, express or implied, or assumes any legal liability or responsibility for the accuracy, completeness, or usefulness of any information, apparatus, product, or process disclosed, or represents that its use would not infringe privately owned rights. Reference herein to any specific commercial product, process, or service by trade name, trademark, manufacturer, or otherwise does not necessarily constitute or imply its endorsement, recommendation, or favoring by the United States Government or any agency thereof. The views and opinions of authors expressed herein do not necessarily state or reflect those of the United States Government or any agency thereof.
\end{abstract}

*Work partially supported by the U.S. Department of Energy , Division of Basic Energy Sciences-Materials Sciences, (RTK, KEG, DMB) Office of Storage and Distribution (DJM, DBM) under contract \#W-31-109. ENG-38 and the National Science Foundation -- Office of Science and Tecinnology Centers under contract \#STC-8809854 (JMG).

The submitled manuscripe has been authored by a contractor of the U.S. Government under contract No. W.31-100-ENG-38. Accordingly, 


\title{
MECHANISMS CONTROLLING THE IN-SITU FORMIATION AND SUPERCONDUCTING PROPERTIES OF BI-SR-CA.CU-O FILMS
}

\author{
R.T. Karmpwirth, J.M. Grace, D.J. Miller, D.B. McDonald, K.E. Gray, M. Reiten, \\ M. Ascolese, and H. Latvakoski \\ Materials Science Division and Science and Technology Center for Superconductivity, \\ Argonne National Laboratory, Argonne, IL 60439
}

\section{Abstract}

We have previously shown $n^{3,6}$ that sputtered films of $\mathrm{Bi}_{2} \mathrm{Sr}_{2} \mathrm{CaCu}_{2} \mathrm{O}_{x}$ (BSCCO) deposited onto single crystal $\mathrm{MgO}$ substrates held al substrate temperatures, $\mathrm{T}_{S}$, near $700^{\circ} \mathrm{C}$ and slowly cooled in oxy'gen, form High 'Temperature Superconducting (HTS) films with $\mathrm{T}_{\text {czero }}$ between 50 and $70 \mathrm{~K}$. The conditions necessary to achieve superconductivity include having close to stoichiometric composition at the $T_{s}$ required to form the superconductor. Both. $\mathrm{T}_{\text {czero }}$ and $\mathrm{c}$-axis orientation increase with $\mathrm{T}_{\mathrm{S}}$ while the relative bismuth content decreases. Bismuth film content is affected by the type and amount of oxidant, total system pressure, target-to-substrate spacing, and substrate bias. We suggest oxygen resputtering of the film may play a role similar to that reported for $\mathrm{YBa}_{2} \mathrm{Cu}_{3} \mathrm{O}_{7} \cdot \mathrm{x}$ (YBCO). Oxygen partial pressure during and cooldown rate from $\mathrm{T}_{\mathrm{S}}$ to $=350^{\circ} \mathrm{C}$ also affects the superconducting properties.

\section{Introduction}

Low-temperature, in-situ processing of HTS YBCO has received considerable attention recently with many researchers demonstrating that the best results are obtained from films grown epitaxially 1 . Less attention has been paid to in-situ processing of thin films of the HTS cuprates based on Bi and Tl, in spite of their potential for higher $T_{c}$, fewer insulating impurity phases, and $c$-axis orientation without the requirement for expitaxy $y^{2}$. Growth of HTS Tl-based filins by in-situ processing has shown little progress presumably because of the extreme volatility of $T 7$ at the growth temperatures needed. However several recent papers ${ }^{3-7}$ report progress on in-situ growth of BSCCO.

This paper reports on the in-situ formation of superconducting films of $\mathrm{Bi}_{2} \mathrm{Sr}_{2} \mathrm{CaCu}_{2} \mathrm{O}_{\mathrm{x}}$ and $\mathrm{Bi}_{2} \mathrm{Sr}_{2} \mathrm{Ca}_{2} \mathrm{Cu}_{3} \mathrm{O}_{x}$. using composite-target sputtering with substrate temperatures, $\mathrm{T}_{s}$, significantly less than required for post-annealed films. We will also discuss $\mathrm{Bi}$ loss in our films relarive to the target, and how it is affected by the type and amount of oxidant present, tota' system pressure, target-to-substrate spacing, substrate bias and $\mathrm{T}_{\mathrm{s}}$. Electron microscopy reveals that the films are polycrystalline with grains several microns in diameter, relatively free of intemal defects such as intergrowths, are somewhat smoother than post-annealed films, and that some segregation into nonsuperconducting grains ${ }^{3}$ can occur.

\section{Film Preparation and Characterization}

All films were grown in a dc magnetron sputtering system equipped with a load-lock mechanism, and a variable speed turbo purnp to control pressure during sputtering. Composite targets were formed by cold-pressing the appropriate amount of calcined powders of the carbonates and oxides into a 1.75 inch diarneter by 0.125 inch thick disk. Further heat treating was necessary to lower the resistance sufficiently for do sputtering. Prior to depositing films, targets were presputtered for several hours to establish equilibrium conditions. The chamber and target were not exposed to atmospheric conditions once presputtering had been completed; rather the system was brought to one atmosphere of nitrogen or oxygen between runs and further protected by the load lock during sample changes. This procedure was found necessary to keep the larget resistance low enough to permit repeated dc sputtering. Films were sputtered at a rate of $5-10 \mathrm{~nm} / \mathrm{min}$. onto single crystal $\mathrm{MgO}$ substrates facing the target and located $25-50 \mathrm{~mm}$ from the target, and in an atmosphere of 4-300 mtorr research grade $\mathrm{Ar}$ with an $\mathrm{O}_{2}$ partial pressure of 0.3 50 miorr or pure oxygen at $300 \mathrm{mtorr}$.

Manuscript received September 24, 1990
Substrates were bonded to a stair' is steel heater block using silver paine. Although this method work : well, there was still some evidence of non-uniform bonding with the possibility of small temperature gradients $\left(<10^{\circ} \mathrm{C}\right)$ across the sample surface. Substrate temperature $\mathrm{T}_{S}$ was measured and controlled over the range from $650-750^{\circ} \mathrm{C}$ using a type- $\mathrm{K}$ thermocouple embedded in the heater block. A second thermocouple, used to calibrate the block the mocouple against the substrate surface temperature, was bonded to the surface of a piece of substrate material which was bonded to the heater block. At $\mathrm{T}_{\mathrm{s}}=700^{\circ} \mathrm{C}$, the surface thennocouple never read more than $20^{\circ} \mathrm{C}$ lower than than $\mathrm{T}_{\mathrm{s}}$.

Filrn compositions were measured by electron-induced $x$-ray fluorscence (done in a scanning electron microscope) and photoninduced $x$-ray fluorescence, calibrated with a single-crystal $\mathrm{Bi}_{2} \mathrm{Sr}_{2} \mathrm{CaCu}_{2} \mathrm{O}_{\mathrm{x}}$ standard and ICP-AES analysis of these films. The photon-induced method employs a $\mathrm{Cr}$-target $\mathrm{x}$-ray tube to excite atomic fluorescence lines in the films. A standard SiLi detector is used and the results obtained take into account $x$-ray absorption in the film, which for the energies, film thickness and geometries used, are small effects. The error is estimated to be $\approx 2 \%$ of the amount present for a film of nominal 2212 composition.

\section{$\underline{\text { Results }}$}

Making superconducting films of the $\mathrm{Bi}-\mathrm{Sr}-\mathrm{Ca}-\mathrm{Cu}$ oxide using composite target sputtering and low temperature in-situ processing with results such as those shown in Fig. 1, require a careful balance between substrate temperature, film stoichiometry, target composition, total system pressure, oxygen partial pressure, and cooldown conditions. For example, films rapidly cooled at high oxygen pressure $(\approx 1 \mathrm{~atm})$ or slow-cooled at a lower oxygen pressure ( 1 torr) or cooled in nitrogen, argon or a vacuum showed either semiconducting or insulating rather than superconducting behavior. It was necessary to slow-cool (we use $6^{\circ} \mathrm{C} / \mathrm{min}$ ) the films in a high pressure (400 torr to $1 \mathrm{~atm}$ ) of oxygen to obtain superconductivity.

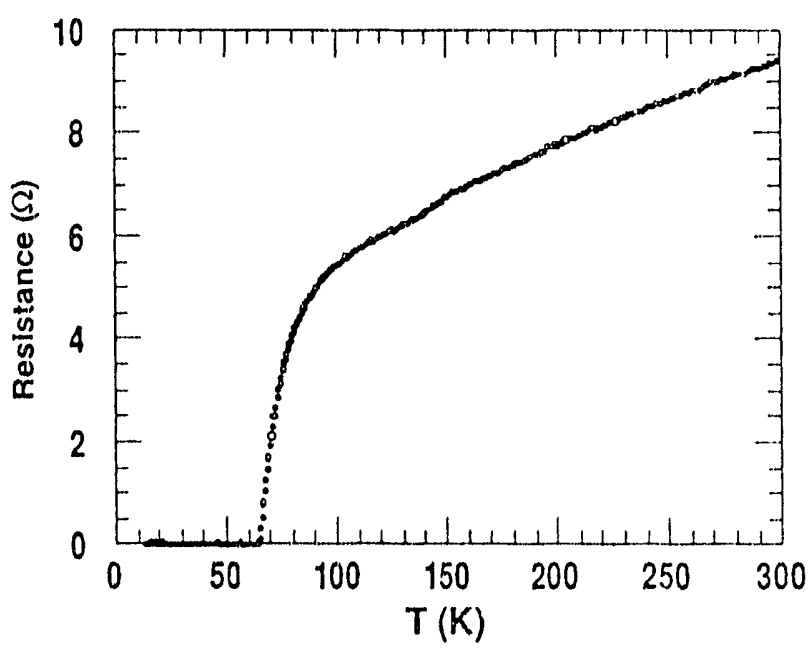

Fig. 1. Resistive transition for in-situ processed BSCCO film. $\mathrm{T}_{\text {czero }} \approx 64 \mathrm{~K}$.

Biloss

Films deposited at 20 mtorr $\mathrm{Ar}$ and $\approx 1$ mtorr $\mathrm{O}_{2}$ show sıgnificant $\mathrm{Bi}$ loss with increasing $\mathrm{T}_{S}$, without a similar loss of $\mathrm{Sr}$, $\mathrm{Ca}$, or $\mathrm{Cu}$. To compensate for $\mathrm{Bi}$-loss, the target $\mathrm{Bi}$ content was 
increased to approximately twice the nomal amount. The results, shown in Fig. 2 for a 3.6,2,2,3 target and a 4,2,1,2 target indicate that for $\mathrm{T}_{\mathrm{s}} \leq 720^{\circ} \mathrm{C}$ doubling the target $\mathrm{Bi}$ content results in approximately the correct $\mathrm{Bi}$ in the filin, whereas above $720^{\circ} \mathrm{C}$ a dramatic drop occurs. The loss of $\mathrm{Bi}$ may be due to a variety of causes such as the inability to completely oxidize $\mathrm{Bi}$, improper amounts of the $n$ :her constitcents resulting in free $\mathrm{Bi}$ or $\mathrm{Bi}_{2} \mathrm{O}_{3}$ which may volatilize away. At $700^{\circ} \mathrm{C}$, the loss rates for $\mathrm{Bi}, \mathrm{Sr}$, and $\mathrm{Ca}$ are orders of magnitude greater $v$ hile $\mathrm{Cu}$ is much less than our deposition rate. The oxides of $\mathrm{Sr}, \mathrm{Ca}$, and $\mathrm{Cu}$ are very stable at this

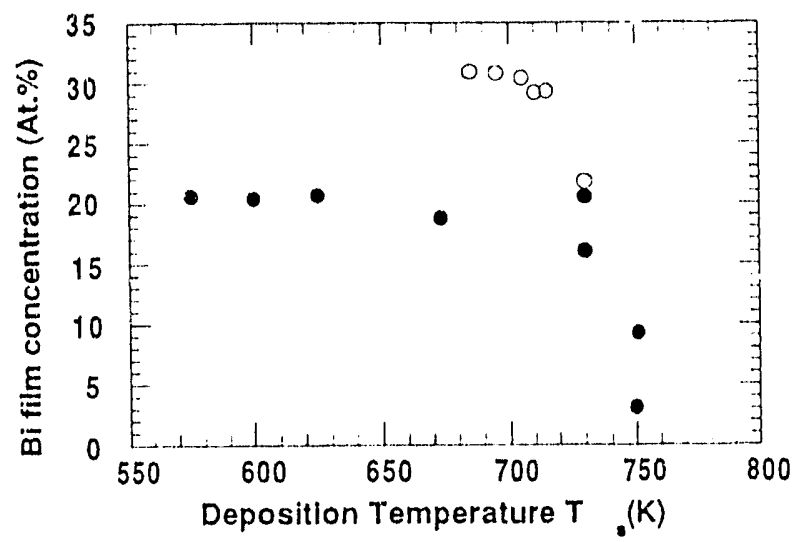

Fig. 2. The effect of in situ processing on the $B i$ concentration as a function of substrate temperature $T_{s}$ for a $4,2,1,2$ target (open circles) and a 3.6,2,2,3 target (solid circles). At $\mathrm{T}_{s}=\mathrm{T}_{\mathrm{amb}}$, the film Bi concentration is $\approx 44$ At. \% for the $4,2,1,2$ target and $\approx 34$ At. \% for the $3.6,2,2,3$ target.

temperature whereas $\mathrm{Bi}_{2} \mathrm{O}_{3}$ will evaporate faster than our deposition rate unless it is bound into a compound oxide such as the $\mathrm{BSCCO}$ crystal structure. One would expect that the binding energy of $\mathrm{Bi}_{2} \mathrm{O}_{2}$ is temperature dependent, therefore the temperature dependence shown in Fig. 2 could be explained as a thermally driven desorption process. Since the oxides of $\mathrm{Ca}$ and $\mathrm{Sr}$ are more readily formed than $\mathrm{Bi}_{2} \mathrm{O}_{3}$ incomplete oxidation could explain the preferential $\mathrm{Bi}$ loss.

To test the idea of incomplete oxidation of $\mathrm{Bi}$, a series of experiments were performed using higher oxygen partial pressures and a stronger oxidizer namely ozone. Increasing the $\mathrm{O}_{2}$ partial pressure from 1 to $10 \mathrm{mtorr}$ while holding the total pressure constant at 20 mtorr produced a decrease in $\mathrm{Bi}$ by more than a factor of three. Ozone in concentrutions considerably less than those used for $\mathrm{O}_{2}$, gave an even greater Bi loss. Since more oxygen or a stronger oxidizer should have reduced $\mathrm{Bi}$ loss if incomplete oxidation were the prime loss mechanism, it seems likely that another mechanism is at work. Researchers sputtering YBCO had observed selective Barium loss and explained it in terms of negative oxygen ion resputtering however no such observations have been reporied for BSCCO. Negative oxygen ions can be formed if the energy from tre plasma splits $\mathrm{O}_{2}$ into $\mathrm{O}$ wlich can pick up an electron from the ample supply in the plasma. Similarly $\mathrm{O}_{3}$ can split even more easily into $\mathrm{O}_{2}$ and $\mathrm{O}$ with the $\mathrm{O}$ picking up an electron. The $\mathrm{O}^{-}$is then repelled trom the target with the sputtering voltage which in our case is $=200$ volis. These ions can lose energy as they inter act with the sustem g 's pressure, however because of the electric field between the negative target and the substrate, they can be re-accelerated with enough energy so that by the time they reach the substrate they exiee, the $\approx 50 \mathrm{eV}$ sputtering threshold and resputter some film.

If resputtering due to nagative oxygen ions is a factor in $\mathrm{Bi}$ loss then reducing or increasing the average energy of the ions striking the film should reduce or increase Bi loss. To test this, the substrate was biased at 40 volts relative to ground in order to reduce the energy of incoming farticles or deflect them away from the substrate entirely. Results showed that the Bi loss could be reduced significrntly. Decreasing or increasing the total pressure while keeping the oxygen partial pressure constant will reduce or increase the number of collisions thereby increasing or reducing the average incident ion energy Lowering the total pressure 105 mrorr reduced the $\mathrm{Bi}$ content as night be expected while increasing the total pressure to as high as 300 mtorr brought the Bi pressure up to target concentrations. We also sputtered in pure oxygen at $300 \mathrm{mtorr}$ (at half the target-to-substrate spacing of the 300 mtorr $\mathrm{Ar} / \mathrm{O}_{2}$ experiment) and found the Bi film content to be slightly less than that obtained from the 300 mtorr $\mathrm{Ar} / \mathrm{O}_{2}$ mixture, suggesting that high gas pressure is important to lowering negative oxygen ion energies to below the resputtering threshold. $\mathrm{Bi}$ loss at $300 \mathrm{mtorr} \mathrm{O}_{2} \mathrm{might}$ be explained as follows. The Bi flux at the substrate was less (the film was thinner than the 300 mtorr $\mathrm{Ar} / \mathrm{O}_{2}$ film even though it was much closer to the target) and the $\mathrm{O}^{-}$flux was greater (6 times more oxygen than the 300 mtorr $\mathrm{Ar} / \mathrm{O}_{2}$ experiment), thus the probability of a resputtering event occurring was increased. A film made at 300 mtorr $\mathrm{O}_{2}$ and $25 \%$ closer to the target than the previous 300 mtorr $\mathrm{O}_{2}$ film showed even less $\mathrm{Bi}$. The results of the $\mathrm{Bi}$ loss experiments are summarized in table 1 .

\begin{tabular}{|c|c|c|c|}
\hline $\begin{array}{c}\text { Total Pressure } \\
\text { mtorr }\end{array}$ & $\begin{array}{l}\text { Oxy.partpres } \\
\text { mtorr }\end{array}$ & $\begin{array}{c}\text { Substrate Bias } \\
\text { volts }\end{array}$ & $\begin{array}{l}\text { Bi in film } \\
\% \text { of target } \mathrm{Bi}\end{array}$ \\
\hline 5 & 1 & 0 & 56 \\
\hline 5 & $i$ & -40 & 61 \\
\hline 20 & 1 & 0 & 76 \\
\hline 20 & 4.5 & 0 & 65 \\
\hline 20 & 10 & 0 & 23 \\
\hline 75 & 12.5 & 0 & 77 \\
\hline 150 & 25 & 0 & 100 \\
\hline 300 & 50 & 0 & 100 \\
\hline 300 & 300 & 0 & 86 \\
\hline 20 & 0.1 (ozone) & 0 & 16 \\
\hline 20 & 0.1 (ozone) & -40 & 67 \\
\hline
\end{tabular}

\section{Substrate Temperature Effects}

Substrate temperatures below $650^{\circ} \mathrm{C}$ generally produce semiconducting or insulating films presumably due to lack of sufficient thermal energy to form a well-ordered HTS phase. At higher substrate temperatures, there is more thermal energy available and film quality improves. But as we previously discussed, at temperatures above $730^{\circ} \mathrm{C}$, severe $\mathrm{Bi}$ loss occurs and films are almost always insulating. Inbetween these extremes, it is possible to form superconducting films of varying quality with the best films made at temperatures near $700^{\circ} \mathrm{C}$. Fig. 3 shows the effect of $\mathrm{T}_{\mathrm{S}}$ on $\mathrm{T}_{\mathrm{czero}}$ and $\mathrm{T}_{\mathrm{c} \text { midpoint }}$ while holding all other conditions constant.

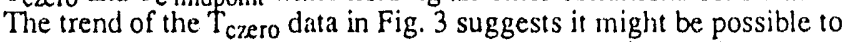
achieve midpoint transitions above $80 \mathrm{~K}$ and $\mathrm{T}_{\text {czero }}$ 's near $80 \mathrm{~K}$ by raising $T_{S}$ to $\approx 740$ to $760^{\circ} \mathrm{C}$. However, hope of actually accomplishing this depends on finding a ways to reduce Bi loss at higher temperatures, such as substrate bias and higher pressure during deposition.

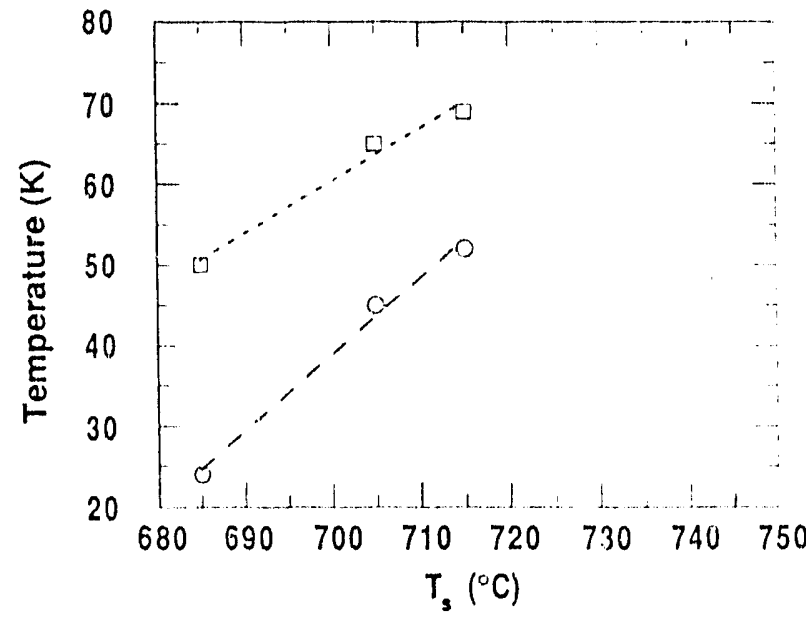

Fig. 3. Effect of substrate temperature on $\mathrm{T}_{\mathrm{czero}}$ (circles) and $\mathrm{T}_{\mathrm{c}}$ midpoint (squares). 
Although diffraction patfens of our in-situ processed 2212 films show a very high degree of caris orientation, films made berween 685 and $695^{\circ} \mathrm{C}$ have rather boud rocking curves with a FWHM $=2-3$ degrees, suggesting many $c$-axis planes are at orienations other than the plane of the film. However, for $T_{S} \geq 705^{\circ} C^{\circ}$ the FWHM drops abruptly $10<1$ deg. which is better than of our typical post-annealed films. and equal to high quality 2212 single crystals ${ }^{8}\left(T_{\text {crero }}=86 \mathrm{~K}\right.$ ) as can be seen in Fig. 4. Although the single crystal peaks appear sharper, the FVHM rocking cune values of 0.7 degrees for the film and 0.6 degrees for the single crystal are quite close. The broadened film diffraction peaks may be a consequence of phase inhomogeneities and the polycrystalline nature of the film.

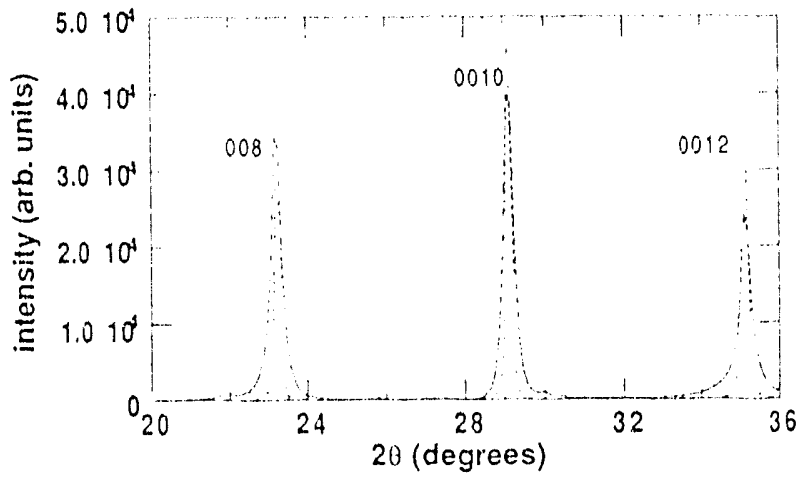

Fig. 4. X-ray diffraction pattem of an in-situ processed $\mathrm{BSCCO}$ 2212 fum (solid line) made at $T_{\mathrm{s}}=715^{\circ} \mathrm{C}$, compared to a $\mathrm{BSCCO}$ 2212 single crystal with a $T_{\text {czero }}=86 \mathrm{~K}$. The film shown here had a $\mathrm{T}_{\mathrm{czcro}} \approx 5+\mathrm{K}$

\section{Microstructure}

The microstructures of these films have been examined using scanning electron microscopy (SEM) and the composition has been determined using $\mathrm{x}$-ray energy dispersive spectroscopy (XEDS). The microstructures consist of a smooth matrix phase with some second phase particles. When viewed at low magnifications, the films often exhibited a somewhat mottled appearance. Closer examination reveals that this mouling is in effect of variations in the number density and size of the second phase particles. Although there are some variations in microstructure from region to region within a given film, comparison between the films has shown that the microstructures are similar at all substrate temperatures, with the second phase purticles growing in size as the substrate temperature increases. An example is shown in Fig. 5 for a fiims grown at $695^{\circ} \mathrm{C}$ and $710^{\circ} \mathrm{C}$. The presence of the second phaze particles does introduce some roughness to the surface since they are observed to grow out of the smooth matrix. In regions of the film where the particle-density is low, the matrix is very smooth over large distances. Transmission electron microscopy (TEM) of film cross sections has revealed some details of the nature of the matrix grains An example of such a cross section is shown in Fig. 6. The matrix grauns can be identified as the 2212 phase through electron diffraction pattems and $c$-axis lattice fringe spacings. The trains are typically several micions in diameter, relatively free of intemal deferts such as intergrowths, and frequently meet at low angle boundaries. In the SEM images, some holes are typically observed in the film, and those holes seem to be associated with regions that have a high density of second phase particles. As the substrate temperature is increased, the microstructure is seen to coarsen somewhat, and the second phatse particles begin to assume clearly identifiable

crystallographic features. For example, many of the particles exhibi a suluare profil: and are often ohserved to possess growth ledges.

$\because E D S$ analysis of these particles in the most coarse microstructures in which these particles may be isolated from the matrix phase has shown them to exhibit a composition close to $\mathrm{Bi}_{2} \mathrm{Sr}_{2} \mathrm{Ca}_{1} \mathrm{O}_{x}$
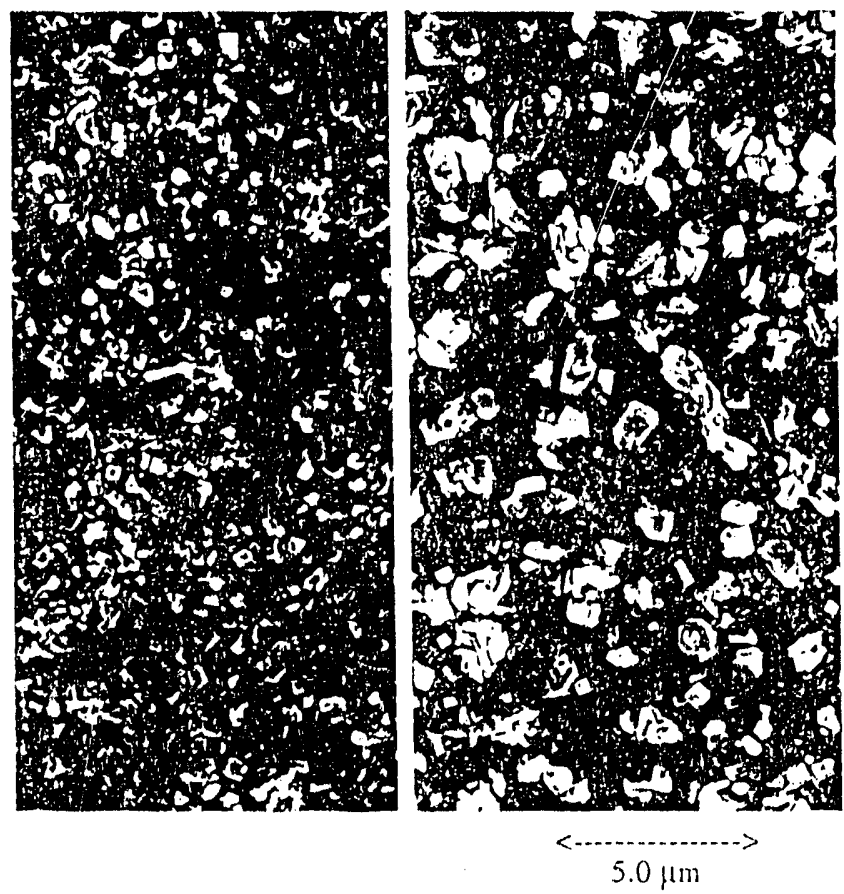

Fig. 5. SEM backscattering images of films made at $695^{\circ} \mathrm{C}$ (left side) and $710^{\circ} \mathrm{C}$ (right side). The particles protruding from the surface grow in size and number-densiry as $\mathrm{T}_{\mathrm{S}}$ increases, but have a composition similar to the underlying matrix.

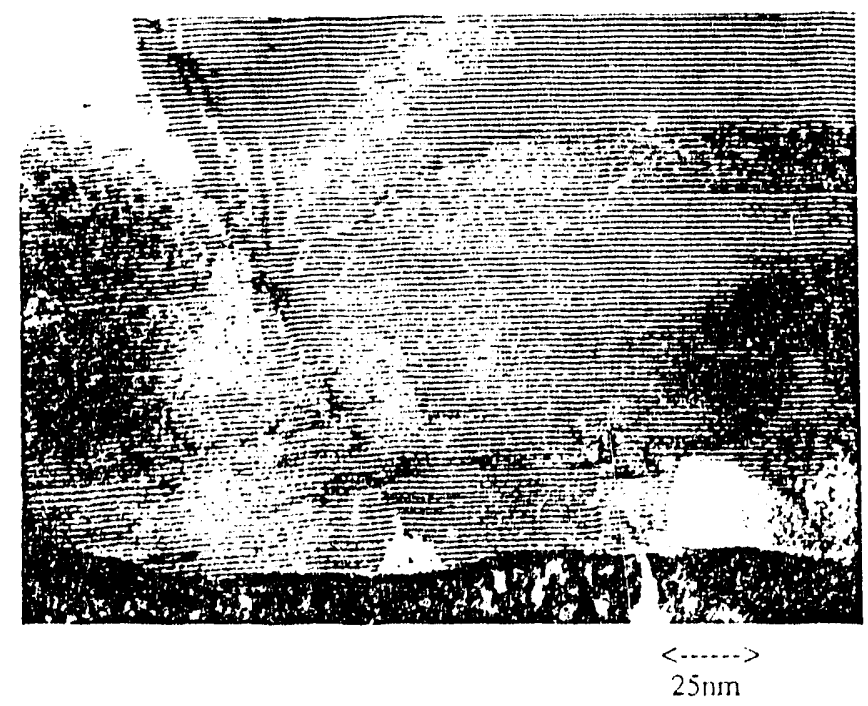

Fig. 6. Crossection TEM of superconducting BSCCO 2212 film made at $\mathrm{T}_{\mathrm{S}}=705^{\circ} \mathrm{C}$ trom a $4,2,1,2,2$ target composition. Note the individual grains and lattice planes relatively free of intergrowths and other defects.

\section{Cim the BSCCO 2223 phase be forned in-situ?}

By using a Bi-enriched 4,2,2,3 target and depositing at a substrate temperatures from $675.720^{\circ} \mathrm{C}$, films with approximately the 2223 stoichiometry can be formed. X-ray diffraction shows peaks associated only with the 2223 Bi-plane spacing (see solid curve in Fir. 7), whereas the $R(\mathrm{l})$ (upper curve in Fig. 8 ) shows metallic behavior with evidence for at transition begimning neat $60 \mathrm{~K}$ and no indication of any $222 \%$ phase. Post-annealing these samples did produce films with a $110 \mathrm{~K}$ partial transition and $T_{\text {czero }}$ at $=6(6) \mathrm{K}$ (iuwer curve in Fig. 8). The $x$ ray pattern (dishlued line in Fig. T) clearly indicates that the 2223 peaks have decreased in size and the 2212 stnucture has tregun to form. Further post-annealing of this film causes more 2212 phatse 10 appear at the expense of the $110 \mathrm{k}$ 
phase. It is possible that what we have is the formation of $\mathrm{Bi}$ bilayers at about the right spacing for the 2223 structure but a disordered structure between the layers which may be deficient in one or more of the other three constituents. Post-annealing orders the structure somewhat but the deficient species (possibly calcium) prevents further ordering and instead drives the structure towards the 2212 phase because for that phase, there is more than enough calcium present.

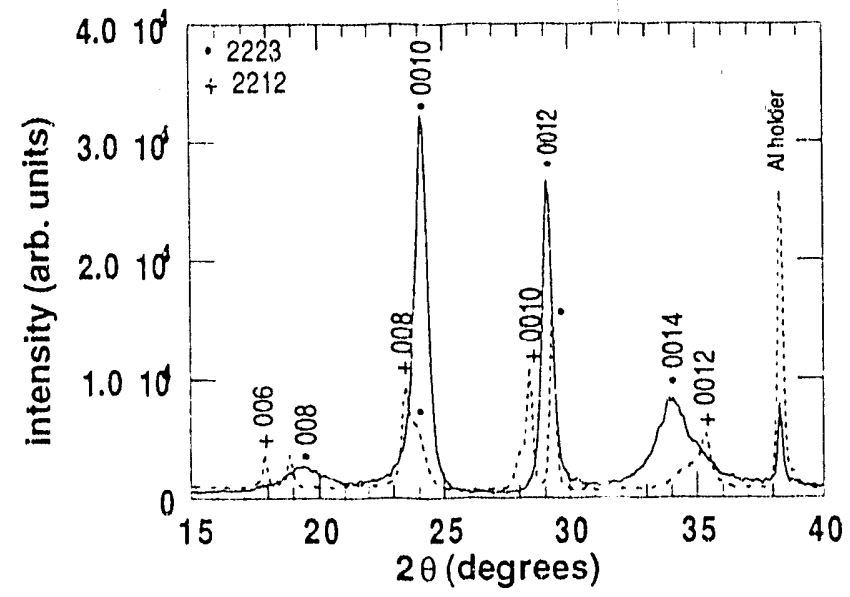

Fig. 7. X-ray diffraction spectra for in-situ processed BSCCO 2223 film (solid line), and same film after post-annealing at $865^{\circ} \mathrm{C}$ for thr (dashed line). All 2223 peaks are designated by a solid circle, whereas the 2212 peaks are indicated by a cross.

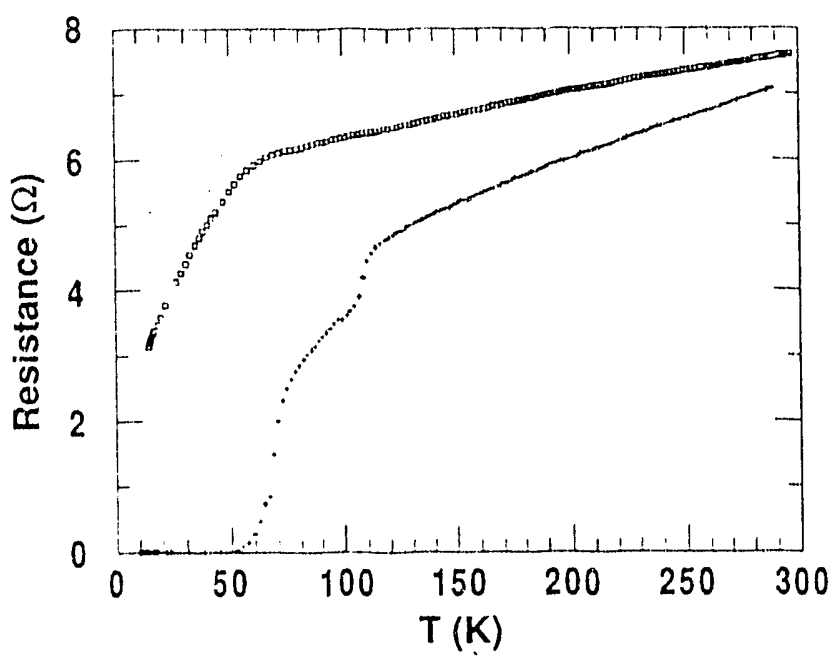

Fig. 8. Resistive transitions for BSCCO 2223 in-situ processed film (upper curve) and the same film afier post-annealing (lower curve).

\section{Summary}

Superconducting iilms of BSCCO 2212 and 2223 can be sputtered onto single crystal $\mathrm{MgO}$ substrates by an in-situ processing technique with $T_{\text {czero's }}$ as high as $64 \mathrm{~K}$, and a very pronounced $\mathrm{c}$-axis orientation without the need for epitaxy. Bi loss in the films can be reduced by biasing the substrate negative or increasing the total system pressure. This should provide greater control over film properties and the possibility of sputter deposition at higher stibstrate temperatures to see if $T_{\text {cyero' }}$ 's close to bulk can be achieved. The uncrostructure generally reveals a smooth matrix with submicron to micron sized particles protruding from it. These particles increase in size and frequency with increasing $T_{S}$ and appear to be a $\mathrm{Bi}-5 \mathrm{~s}-\mathrm{Ca}_{\mathrm{a}}$ oxide mixture.

The exact mechanism by which crystallization occurs during in-situ processing at temperatures $\approx 150^{\circ} \mathrm{C}$ below post-annealing temperatures has not been established. Due to greater atomic mobility amongst the surface atorns compared to that within a bulk film, there is a lower kinetic barrier for nucleation and crystal growth during in-situ processing. Thus the possibility exists that increases in surface energy relative to the underlying film could promote crystal growth at even lower substrate temperatures.

\section{Acknowledgements}

The authors thank J. Stein for help with measurements of the resistive transitions and data acquisition system development, $U$. Balachandran and Sue Kowalsix for making the BSCCO targets, E.A. Huff for JCP-AES measurements, R. Lee for assistance with the electron mi roscopy, and $T$. Roberts for assistance with the $x$-ray fluorescence me asurements. This work was supported by the U.S. Department of Energy, Division of Basic Energy Sciences (RTK, KEG and DMB), Office of Energy Storage and Distribution (DJM and DBM), under contract \#W-31-109-ENG-38 and the National Science Foundation-... Office of Science and Technology Centers under contract \#STC-8809854 (JMG). MR, MA, and LH acknowledge support from the Division of Educational Programs, Argonne National Laboratory.

\section{References}

1. See for example, the Proceedings of the Second Colorado Conference on Science and Technology of Thin Film Superconductors, Plenum Pub. Corp., 1991(to be published).

2. J.H. Kang, R.T. Kampwirth, and K.E. Gray," High critical field anisotropy of superconducting $\mathrm{Bi}-\mathrm{Sr}-\mathrm{Ca}-\mathrm{Cu}$ oxide from highly oriented thin films", Appl. Phys. Lett., 52, 2080-2082, 1988; J.H.

Kang, K.E. Gray, R.T. Kampw:rth, and D.W. Day, "Large anisotropy in the upper critical field of sputtered thin films of superconducting Tl-Ba-Ca-Cu-O", Appl. Phys. Lett., 53, 2560-2562, 1988.

3. R.T. Kampwirth, P.H. Andersen, D.B. McDonald, D.J. Miller, K.E. Gray, Z.F. Sungaila, U. Balachandran, and A. Wagner, "Properties of sputtered superconducting films of $\mathrm{Bi}_{2} \mathrm{Sr}_{2} \mathrm{CaCu}_{2} \mathrm{O}_{x}$ made by low-termperature in situ growth", Appl. Phys. Lett., 55, 2135-2137, 1989.

4. S. Miura, A. Nakai, Y. Shimakawa, T, Yoshitake, Y. Miyasaka, N. Shohata and T. Satoh, "As-grown crystallized thin film of $\mathrm{Bi}-\mathrm{Sr}-\mathrm{Ca}-\mathrm{Cu}-\mathrm{O}$ and its low-temperature annealing effect", Appl. Phys. Lett., 54, 1474-1476, 1989.

5. J. Fujita, T. Yoshitake, H. Igarashi and T. Satoh, "In situ epitaxial growth of $\mathrm{Bi}_{2}(\mathrm{Sr}, \mathrm{Ca})_{3} \mathrm{Cu}_{2} \mathrm{O}_{\mathrm{x}}$ films by ion beam sputtering with an atomic oxygen source", Appl. Phys. Lett., 56, 295-297, 1990.

6. D.G. Schlom, A.F. Marshall, J.T. Sizemore, Z.J. Chen, J.N. Eckstein, I. Bozovic, K.E. von Dessonneck, J.S. Harris, Jr., and J.C. Bravman, "Molecular beam epitaxial growth of layered Bi-Sr-CaCu-O compounds", J. Crystal Growth, 102, 361-375, 1990.

7. R.T. Kampwirth, J.M. Grace, D.J. Miller, D.B. McDonald, K.E. Gray, P.H. Andersen, B. Driehtiys, M. Reiten, and M.

Ascolese, "In-situ growth of superconducting films of $\mathrm{Bi}-\mathrm{Sr}$-Ca-Cu$O$ using magnetron sputtering", To lee published in Proceedings of the Second Colorado Conference on Science and Technology of Thin Film Superconductors, Plenum Pub. Corp., 1991 (to be published).

8. Single crystal supplied by D. Shi, Materials Science Division, Argonne National Laboratory. 

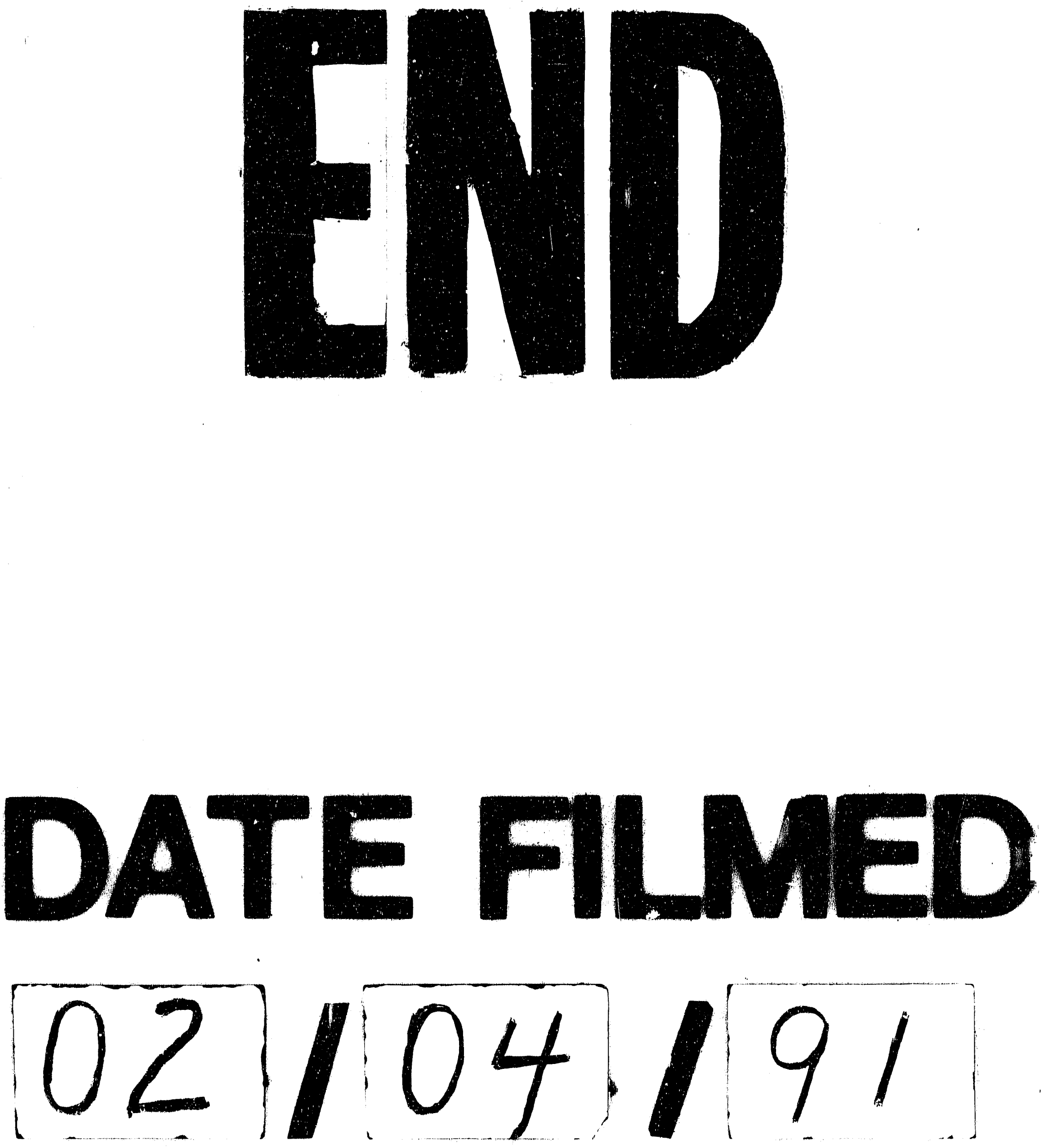
